\title{
Content and Quality of Information Websites About Congenital Heart Defects Following a Prenatal Diagnosis
}

Tommy Carlsson ${ }^{1}$, RN, PGDip, MMSc; Gunnar Bergman ${ }^{2}$, MD, PhD; Anna-Malin Karlsson ${ }^{3}$, PhD; Elisabet Mattsson ${ }^{1,4}$, RNM, PhD

\footnotetext{
${ }^{1}$ Department of Public Health and Caring Sciences, Uppsala University, Uppsala, Sweden

${ }^{2}$ Department of Women's and Children's Health, Karolinska Institutet, Stockholm, Sweden

${ }^{3}$ Department of Scandinavian Languages, Uppsala University, Uppsala, Sweden

${ }^{4}$ Department of Women's and Children's Health, Uppsala University, Uppsala, Sweden
}

\section{Corresponding Author:}

Tommy Carlsson, RN, PGDip, MMSc

Department of Public Health and Caring Sciences

Uppsala University

BMC Husargatan 3

Box 564

Uppsala, S-75122

Sweden

Phone: 46736143454

Fax: 46184716675

Email: tommy.carlsson@pubcare.uu.se

\section{Abstract}

Background: Pregnant women and their partners use the Internet to search for information following a prenatal diagnosis of congenital heart defect.

Objective: Our aim was to explore central subjects of content and to assess the accessibility, reliability, usability, and quality of written information on publicly available information websites about congenital heart defects following a prenatal diagnosis.

Methods: Following searches on Bing and Google, we included websites containing patient information in English. Hits ranged from 340,000-67,500,000 and the first 50 hits from each search were screened for inclusion (N=600). Of these hits, 39.3\% $(236 / 600)$ were irrelevant. A total of 67 websites were included, of which 37\% (25/67) were affiliated with independent information websites, 25\% (17/67) with charity/private organizations, 25\% (17/67) with hospitals/clinics, and 13\% (8/67) had other affiliations. The majority of the websites $(76 \%, 51 / 67)$ could not be attributed to an author. A manifest content analysis was performed to explore central subjects of content. The DISCERN instrument was used to assess the quality of information, and the LIDA tool was used to assess accessibility, usability, and reliability of the included websites.

Results: The content on the majority of the websites included care and treatment of children with congenital heart defects $(88 \%$, $59 / 67)$, causes of congenital heart defects $(88 \%, 59 / 67)$, symptoms of congenital heart defects $(85 \%, 57 / 67)$, prevalence of congenital heart defects $(81 \%, 54 / 67)$, potential complications of congenital heart defects $(75 \%$, 50/67), prenatal diagnostics/screening methods (72\%, 48/67), and specific congenital heart defects $(72 \%, 48 / 67)$, whereas less than $10 \%$ included information about termination of pregnancy $(6 \%, 4 / 67)$, care during pregnancy $(5 \%, 3 / 67)$, and information specifically directed to partners $(1 \%, 1 / 67)$. The mean of the total DISCERN score was 27.9 (SD 9.7, range 16-53). According to the instrument, a majority of the websites were categorized as very poor regarding information about effects of no treatment (88\%, 59/67), support for shared decision making $(85 \%, 57 / 67)$, achievement of its aims $(84 \%, 56 / 67)$, explicit aims $(82 \%, 55 / 67)$, risks of each treatment $(82 \%, 55 / 67)$, how treatment choices affect overall quality of life $(76 \%, 51 / 67)$, and areas of uncertainty $(76 \%, 51 / 67)$. The mean of the total LIDA score was 92.3 (SD 13.1, range 61-127). According to the tool, a majority of the websites were categorized as good with regard to registration $(97 \%, 65 / 67)$ and browser test $(75 \%, 50 / 67)$, whereas a majority were categorized as poor with regard to currency $(87 \%, 58 / 67)$, content production $(84 \%, 56 / 67)$, and engagability $(75 \%, 50 / 67)$.

Conclusions: Difficulties in finding relevant information sources using Web search engines and quality deficits on websites are an incentive for health professionals to take an active part in providing adequate and reliable information online about congenital heart defects. 
(Interact J Med Res 2015;4(1):e4) doi:10.2196/ijmr.3819

\section{KEYWORDS}

consumer health information; heart defects, congenital; Internet; prenatal diagnosis

\section{Introduction}

Globally, an increasing number of health care consumers use the Internet to search for health-related issues [1-4]. The Internet has the potential to provide highly accessible, interactive, and tailored information. However, this might be limited by navigational difficulties and inaccurate or misleading information that has not been peer-reviewed [5,6]. Although many individuals have little or no trust in Internet information, it is used as a primary source when searching for health-related information [7]. Studies of literacy practices in relation to health communication have shown that trustworthiness is the key issue for patients assessing health information. For example, pregnant women in the United Kingdom were shown to search for texts written by medical professionals or published by medical institutions, thus appraising authority on the basis of their trust in academic and professional expertise [4].

Advances in prenatal screening have improved the detection rate of fetal diagnoses of congenital heart defects (CHD) [8,9]. Following diagnosis, counseling from health professionals is essential regarding a wide range of topics, including, for example, the nature and consequences of the CHD, severity, treatments available, prognosis, postoperative complications, and possible associations of CHD with other diseases [10,11]. Based on the information received, the pregnant woman also has the option of and the responsibility for deciding whether or not to terminate the pregnancy. Depending on national legislation on termination of the pregnancy, the decision must often be made soon after receiving the diagnosis. The process towards an informed decision on the future of the pregnancy involves various difficulties, including comprehending complex medical information [12,13], ethical considerations [14,15] and psychological distress [16]. An online survey among parents of children with CHD revealed that $50 \%$ report that more information at the time of diagnosis would have been helpful [17]. To deal with this matter, pregnant women and their partners try to supplement counseling from health professionals by using the Internet to search for information following the diagnosis [12].

The aim of this study was to explore central subjects of content and to assess the accessibility, usability, reliability, and quality of written information on publicly available information websites about congenital heart defects following a prenatal diagnosis.

\section{Methods}

\section{Data Collection}

In October 2013, the following key terms were entered separately in the two most commonly used search engines, Bing and Google [18]: "Congenital Heart Disease", "Congenital Heart Defect", "Ultrasound Heart Disease", "Ultrasound Heart Defect", "Pregnancy Heart Disease", and "Pregnancy Heart Defect". The inclusion criterion was a website written in English that provided patient information regarding CHD. The search was made in incognito mode in order to minimize influence from previous search patterns. The generated result of the search procedure was saved, and the first 50 hits obtained for each search procedure were screened for inclusion $(\mathrm{N}=600)$. Duplicate websites and direct links to communities/blogs, video materials, and scientific articles were excluded. In total, 533 (88.8\%) were excluded, leaving $67(11.2 \%)$ websites for inclusion in the study. Figure 1 presents the selection process, that is, key terms, hits, and excluded and included websites via Bing and Google, respectively.

The websites we included were affiliated with independent information websites $(25 / 67,37 \%)$, charity/private organizations $(17 / 67,25 \%)$, hospitals/clinics $(17 / 67,25 \%)$, governments $(4 / 67$, $6 \%)$, medical companies $(1 / 67,2 \%)$, and other websites $(4 / 67$, $6 \%$ ). The majority of the websites could not be attributed to an author $(51 / 67,76 \%)$, whereas a minority could be attributed to medical professionals $(10 / 67,15 \%)$, journalists $(2 / 67,3 \%)$, and others $(4 / 67,6 \%)$. 
Figure 1. Selection process for the included websites (N=67; A: Scientific Article; CoB: Community or Blog; D: Duplicate; FP: For Professionals; NR: Not Relevant).

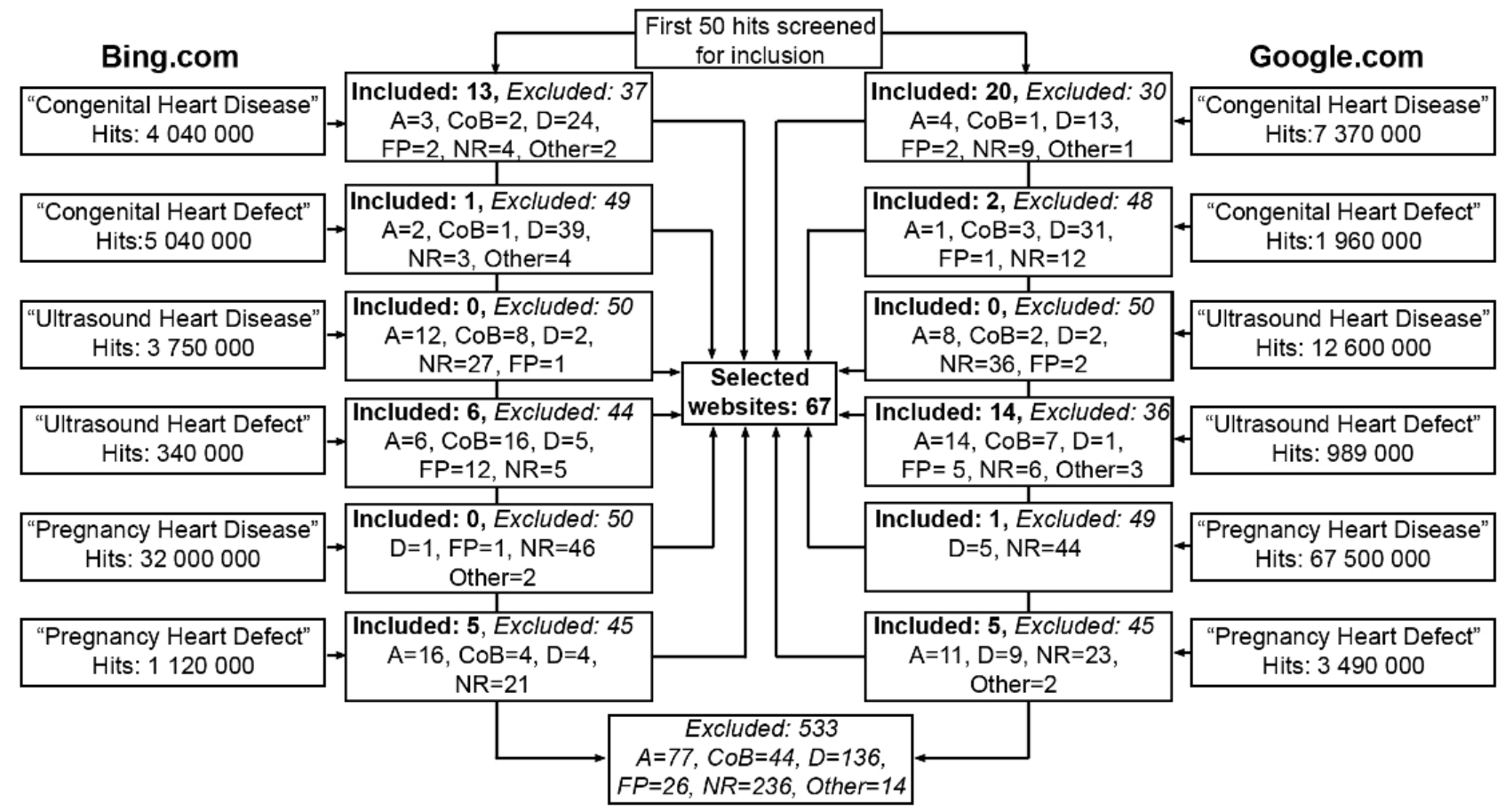

\section{Data Analyses}

\section{Central Subjects of Content}

A manifest content analysis [19] was performed to inductively identify the central subjects of content of each website. The first author read the websites repeatedly. Paragraphs and statements (meaning units) containing relevant information regarding the content of each website were identified and grouped into categories (central subjects). Meaning units in the same category are assumed to have a similar meaning, on the basis of either the precise meaning of text or of texts sharing the same connotations. Thereafter, the websites were read again and subcategories were identified, that is, common characteristics within a larger category. Finally, the websites were all read through once more in order to validate the results.

\section{Assessment of Quality}

The websites were individually evaluated using two standardized instruments: the DISCERN instrument [20] and the Minervation validation instrument for health care websites (LIDA tool, version 1.2) [21]. The first author conducted all assessments of the websites.

The DISCERN instrument is a reliable and valid instrument for assessing the quality of written consumer health information independent of previous knowledge of the field under research [20]. It was developed with the input of an expert panel, health information providers, and patients from a self-help group, and has acceptable levels of interrater agreement [22]. The instrument consists of 16 questions divided into three sections. The user rates each question on a scale ranging from 1 (low/poor) to 5 (high/excellent), resulting in a total score ranging from 16 to 80 . Section 1 includes 8 questions (score ranging from 8-40) and assesses reliability, whereas Section 2 with 7 questions (7-35) focuses on the quality of information about treatment options, that is, in this study continuation/termination of pregnancy, fetal interventions, and treatments of CHD. Section 3 consists of 1 question (1-5) and provides an overall rating of the quality of the websites, based on the responses to the previous questions [20].

The LIDA tool [21] assesses accessibility, reliability, and usability of health care websites. It consists of 29 questions and an automated test. Each question is rated from 0 to 3 (higher being better), and the automated test generates a score of 0-54, resulting in a total score ranging from 0 to 141 . The overall score is calculated as a percentage, where scores greater than $90 \%$ represent good results and less than $50 \%$ poor results [23]. Accessibility (score ranging from 0-60) includes an automated test of page set-up, access restrictions, and outdated code, together with manual registration and browser tests conducted in Apple Safari, Google Chrome, and Mozilla Firefox. Usability (0-54) includes clarity, consistency, functionality, and engagability. Reliability (0-27) includes currency, conflicts of interest, and content production.

\section{Statistical Analysis}

Descriptive statistics were carried out using R (version 3.0.1).

\section{Results}

\section{Central Subjects of Content}

Central subjects of content on the 67 websites were categorized into 25 categories with 46 subcategories (Table 1). 
Table 1. Central subjects of content identified on the included websites $(\mathrm{N}=67)$.

\begin{tabular}{|c|c|c|}
\hline Category & Subcategory & $\mathrm{n}(\%)$ \\
\hline \multicolumn{2}{|c|}{ Care and treatment of children with CHD } & $59(88)$ \\
\hline & Surgery & $59(88)$ \\
\hline & Cardiac catheterization for treatment & $48(72)$ \\
\hline & Medications & $48(72)$ \\
\hline & Cardiac transplantation & $39(58)$ \\
\hline & Nutrition & $18(27)$ \\
\hline & Pacemaker & $17(25)$ \\
\hline & Intensive care & $11(16)$ \\
\hline & Animations or illustrations of treatments & $9(13)$ \\
\hline & Immunizations & $3(5)$ \\
\hline & How to include cultural/spiritual beliefs in the care of the child & $1(1)$ \\
\hline \multicolumn{2}{|c|}{ Causes of CHD } & $59(88)$ \\
\hline \multicolumn{2}{|c|}{ Symptoms of CHD } & $57(85)$ \\
\hline \multicolumn{2}{|c|}{ Prevalence of CHD } & $54(81)$ \\
\hline \multicolumn{2}{|c|}{ Potential complications of CHD } & $50(75)$ \\
\hline \multicolumn{2}{|c|}{ Prenatal diagnostic/screening methods } & $48(72)$ \\
\hline & Fetal echocardiography & $40(60)$ \\
\hline & Amnioscentesis & $15(22)$ \\
\hline & Chorionic villus sampling & $12(18)$ \\
\hline & Nuchal translucency scan & $11(16)$ \\
\hline & Blood tests & $9(13)$ \\
\hline & Risks of invasive methods & $9(13)$ \\
\hline & Umbilical cord sampling & $4(6)$ \\
\hline & Fetal magnetic resonance imaging & $2(3)$ \\
\hline \multicolumn{2}{|c|}{ Specific CHD } & $48(72)$ \\
\hline & Animations or illustrations of CHD & $28(42)$ \\
\hline \multicolumn{2}{|c|}{ Associated anomalies } & $47(70)$ \\
\hline \multicolumn{2}{|c|}{ Normal cardiovascular system } & $46(69)$ \\
\hline & Postnatal cardiovascular system & $42(63)$ \\
\hline & Cardiovascular changes at birth & $35(52)$ \\
\hline & Animations or illustrations of normal cardiovascular system & $29(43)$ \\
\hline & Fetal cardiovascular system & $16(24)$ \\
\hline \multicolumn{2}{|c|}{ Postnatal diagnostic methods } & $45(67)$ \\
\hline & Echocardiography & $43(64)$ \\
\hline & Electrocardiography & $42(63)$ \\
\hline & Physical examination & $42(63)$ \\
\hline & Radiography & $42(63)$ \\
\hline & Cardiac catheterization for diagnosis & $39(58)$ \\
\hline & Pulse oximeter & $25(37)$ \\
\hline & Chemical analyses & $18(27)$ \\
\hline & Exercise test & $16(24)$ \\
\hline \multicolumn{2}{|c|}{ Long-term outlook and care } & $44(66)$ \\
\hline
\end{tabular}




\begin{tabular}{|c|c|c|}
\hline Category & Subcategory & $\mathrm{n}(\%)$ \\
\hline & Monitoring/Follow-up care & $31(46)$ \\
\hline & Dental care/endocarditis prophylaxis & $28(42)$ \\
\hline & Grown-up with CHD & $24(36)$ \\
\hline & Pregnancy with CHD in mother & $24(36)$ \\
\hline & Physical activity & $23(34)$ \\
\hline \multicolumn{2}{|l|}{ Prognosis } & $41(61)$ \\
\hline \multicolumn{2}{|c|}{ Risks of treatment of CHD } & $25(37)$ \\
\hline \multicolumn{2}{|c|}{ Common feelings following prenatal diagnosis of $\mathrm{CHD}$} & $18(27)$ \\
\hline \multicolumn{2}{|c|}{ Postnatal quality of life } & $18(27)$ \\
\hline & Quality of life for the child & $18(27)$ \\
\hline & Quality of life for the family & $5(7)$ \\
\hline \multicolumn{2}{|c|}{ Examples of previous cases that continued the pregnancy } & $16(24)$ \\
\hline \multicolumn{2}{|c|}{ Precision of prenatal diagnosis of CHD } & $16(24)$ \\
\hline \multicolumn{2}{|l|}{ Delivery } & $14(21)$ \\
\hline & Location and planning of delivery & $14(21)$ \\
\hline & Mode of delivery & $1(1)$ \\
\hline \multicolumn{2}{|c|}{ Postnatal coping with the diagnosis } & $13(19)$ \\
\hline & Financial issues & $12(15)$ \\
\hline & Grief and bereavement & $2(3)$ \\
\hline & Information regarding siblings & $2(3)$ \\
\hline \multicolumn{2}{|c|}{ Risks of CHD in future pregnancy } & $10(15)$ \\
\hline \multicolumn{2}{|c|}{ Fetal intervention } & $8(12)$ \\
\hline \multicolumn{2}{|c|}{ Presentation of the multidisciplinary team in care of the child } & $8(12)$ \\
\hline \multicolumn{2}{|c|}{ Termination of pregnancy } & $4(6)$ \\
\hline & Informed and personal decision & $2(3)$ \\
\hline & Time limit & $2(3)$ \\
\hline & Feelings about termination of pregnancy & $1(1)$ \\
\hline \multicolumn{2}{|c|}{ Care during pregnancy } & $3(5)$ \\
\hline \multicolumn{2}{|c|}{ Information specifically directed to partners } & $1(1)$ \\
\hline
\end{tabular}

The majority $(>70 \%)$ of the websites contained information about care and treatment of children with CHD $(88 \%, 59 / 67)$, causes of CHD $(88 \%, 59 / 67)$, symptoms of CHD $(85 \%, 57 / 67)$, prevalence of CHD $(81 \%, 54 / 67)$, potential complications of CHD (75\%, 50/67), prenatal diagnostics/screening methods $(72 \%, 48 / 67)$, and specific CHD (72\%, 48/67). A minority $(<30 \%)$ of the websites contained information about common feelings following prenatal diagnosis of CHD $(27 \%, 18 / 67)$, postnatal quality of life $(27 \%, 18 / 67)$, examples of previous cases that continued the pregnancy $(24 \%, 16 / 67)$, precision of prenatal diagnosis of CHD $(24 \%, 16 / 67)$, delivery $(21 \%, 14 / 67)$, postnatal coping with the diagnosis $(19 \%, 13 / 67)$, risks of CHD in future pregnancy $(15 \%, 10 / 67)$, fetal intervention $(12 \%, 8 / 67)$, presentation of the multidisciplinary team in care of the child $(12 \%, 8 / 67)$, termination of pregnancy $(6 \%, 4 / 67)$, care during pregnancy $(5 \%, 3 / 67)$, and information specifically directed to partners $(1 \%, 1 / 67)$.

\section{Assessment of Quality}

\section{DISCERN}

Table 2 presents means, standard deviations, and ranges of the included websites measured by the DISCERN instrument.

In applying the DISCERN criteria to the evaluation of the websites (Figure 2), the majority of the websites $(>70 \%)$ were categorized as very poor regarding effects of no treatment $(88 \%$, $59 / 67)$, support for shared decision making $(85 \%, 57 / 67)$, achievement of its aims $(84 \%, 56 / 67)$, explicit aims $(82 \%$, $55 / 67)$, risks of each treatment $(82 \%, 55 / 67)$, how treatment choices affect overall quality of life $(76 \%, 51 / 67)$, and areas of uncertainty $(76 \%, 51 / 67)$. 
Table 2. Means, standard deviations (SD), and ranges of the included websites $(\mathrm{N}=67)$ measured by the DISCERN instrument (the maximum achievable scores in shown in brackets after each section and question).

\begin{tabular}{|c|c|c|c|}
\hline Section (max. score) & Question & Mean (SD) & Range \\
\hline \multirow[t]{9}{*}{ Reliability (40) } & & $14.7(5.2)$ & $8-30$ \\
\hline & Explicit aims (5) & $1.5(1.1)$ & $1-5$ \\
\hline & Aims achieved (5) & $1.3(0.7)$ & $1-4$ \\
\hline & Relevance (5) & $2.6(0.8)$ & $1-5$ \\
\hline & Explicit sources (5) & $1.8(1.3)$ & $1-5$ \\
\hline & Explicit date (5) & $1.9(1.1)$ & $1-5$ \\
\hline & Balanced and unbiased (5) & $2.2(1.1)$ & $1-5$ \\
\hline & Additional sources(5) & $2.1(1.3)$ & $1-5$ \\
\hline & Areas of uncertainty (5) & $1.4(0.8)$ & $1-4$ \\
\hline \multicolumn{2}{|c|}{ Treatment options (35) } & $11.1(4.9)$ & $7-25$ \\
\hline & How treatment works (5) & $2.2(1.3)$ & $1-5$ \\
\hline & Benefits of treatment (5) & $2.0(1.1)$ & $1-5$ \\
\hline & Risks of treatment (5) & $1.3(0.8)$ & $1-5$ \\
\hline & Effects of no treatment (5) & $1.3(0.8)$ & $1-5$ \\
\hline & Effects on quality of life (5) & $1.3(0.7)$ & $1-4$ \\
\hline & All options described (5) & $1.7(0.9)$ & $1-4$ \\
\hline & Shared decision (5) & $1.3(0.9)$ & $1-5$ \\
\hline \multicolumn{2}{|l|}{ Overall rating (5) } & $2.1(1.0)$ & $1-4$ \\
\hline \multicolumn{2}{|l|}{ Total (80) } & $27.9(9.7)$ & $16-53$ \\
\hline
\end{tabular}

Figure 2. Proportion of websites $(\mathrm{N}=67)$ categorized into five categories from very poor to excellent, for each separate question in the DISCERN instrument.

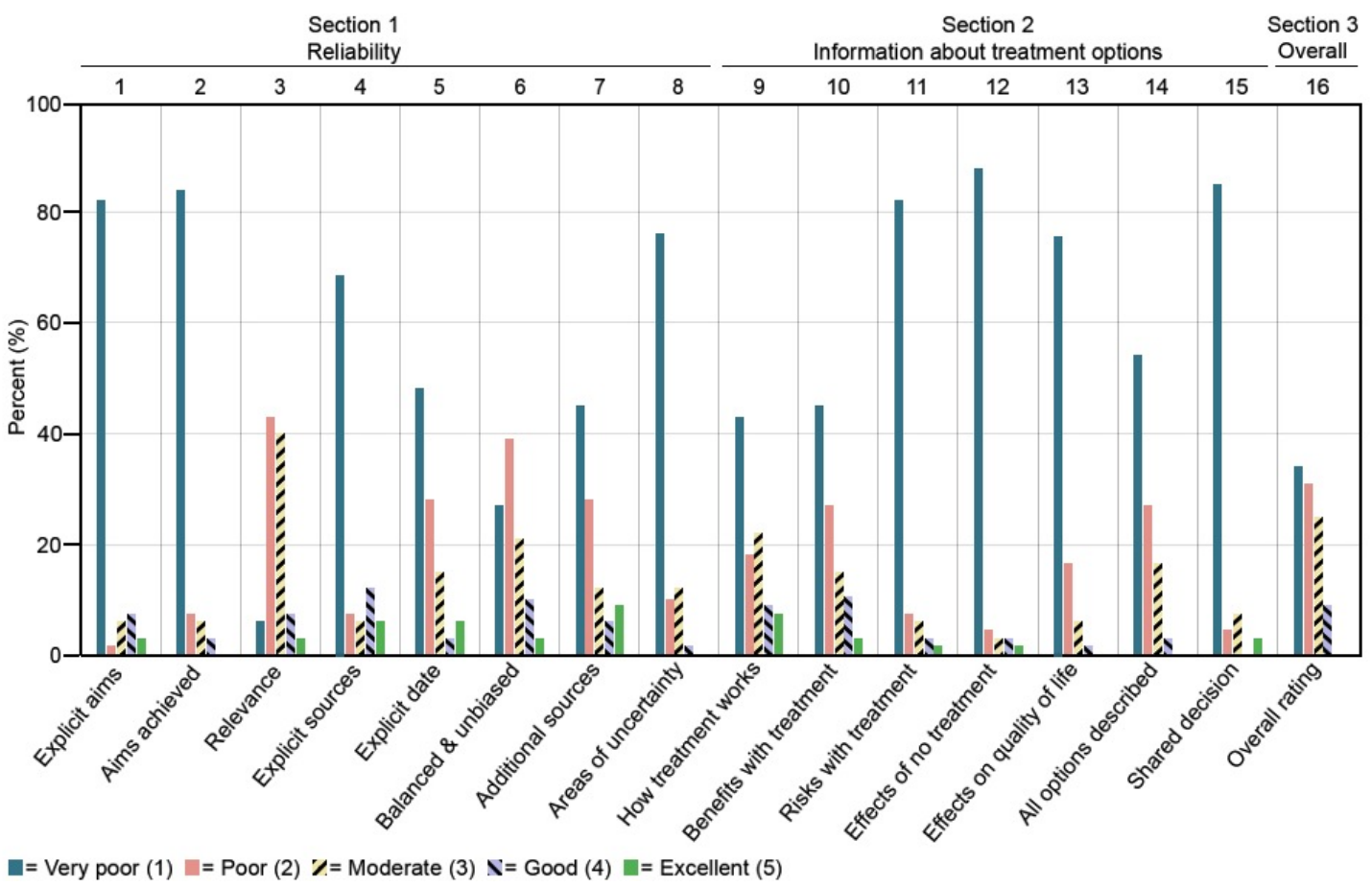

\section{LIDA}

Table 3 presents means, standard deviations (SD), and ranges of the included websites measured by the LIDA tool.
In applying the LIDA criteria to the evaluation of the websites (Figure 3 ), the majority of the websites $(>70 \%)$ were categorized as good regarding registration $(97 \%, 65 / 67)$ and browser test $(75 \%, 50 / 67)$, whereas the majority was categorized as poor 
regarding currency $(87 \%, 58 / 67)$, content production $(84 \%, 56 / 67)$, and engagability $(75 \%, 50 / 67)$.

Table 3. Means, standard deviations, and ranges of the included websites measured by the LIDA tool (the maximum achievable scores in shown in brackets after each section and question).

\begin{tabular}{|c|c|c|c|}
\hline Section (max. score) & Subscale & Mean (SD) & Range \\
\hline \multirow[t]{4}{*}{ Accessibility (60) } & & $50.7(5.3)$ & $37-59$ \\
\hline & Automated test (54) & $45.1(5.4)$ & $31-53$ \\
\hline & Browser test (3) & $2.6(0.7)$ & $1-3$ \\
\hline & Registration (3) & $3.0(0.3)$ & $1-3$ \\
\hline \multirow[t]{5}{*}{ Usability (54) } & & $32.5(7.1)$ & $19-48$ \\
\hline & Clarity (18) & $9.8(3.2)$ & $3-17$ \\
\hline & Consistency (9) & $7.9(1.5)$ & $3-9$ \\
\hline & Functionality (15) & $10.6(2.4)$ & $6-15$ \\
\hline & Engagability (12) & $4.2(2.6)$ & $1-11$ \\
\hline \multirow[t]{4}{*}{ Reliability (27) } & & $8.9(5.4)$ & $0-22$ \\
\hline & Currency (9) & $2.0(1.8)$ & $0-7$ \\
\hline & Conflicts of interest (9) & $5.6(2.9)$ & $0-9$ \\
\hline & Content production (9) & $1.5(2.2)$ & $0-7$ \\
\hline Total (141) & & $92.3(13.1)$ & $61-127$ \\
\hline
\end{tabular}

Figure 3. Proportion of websites $(\mathrm{N}=67)$ categorized into three categories from poor to good, for the subscales and total LIDA score.

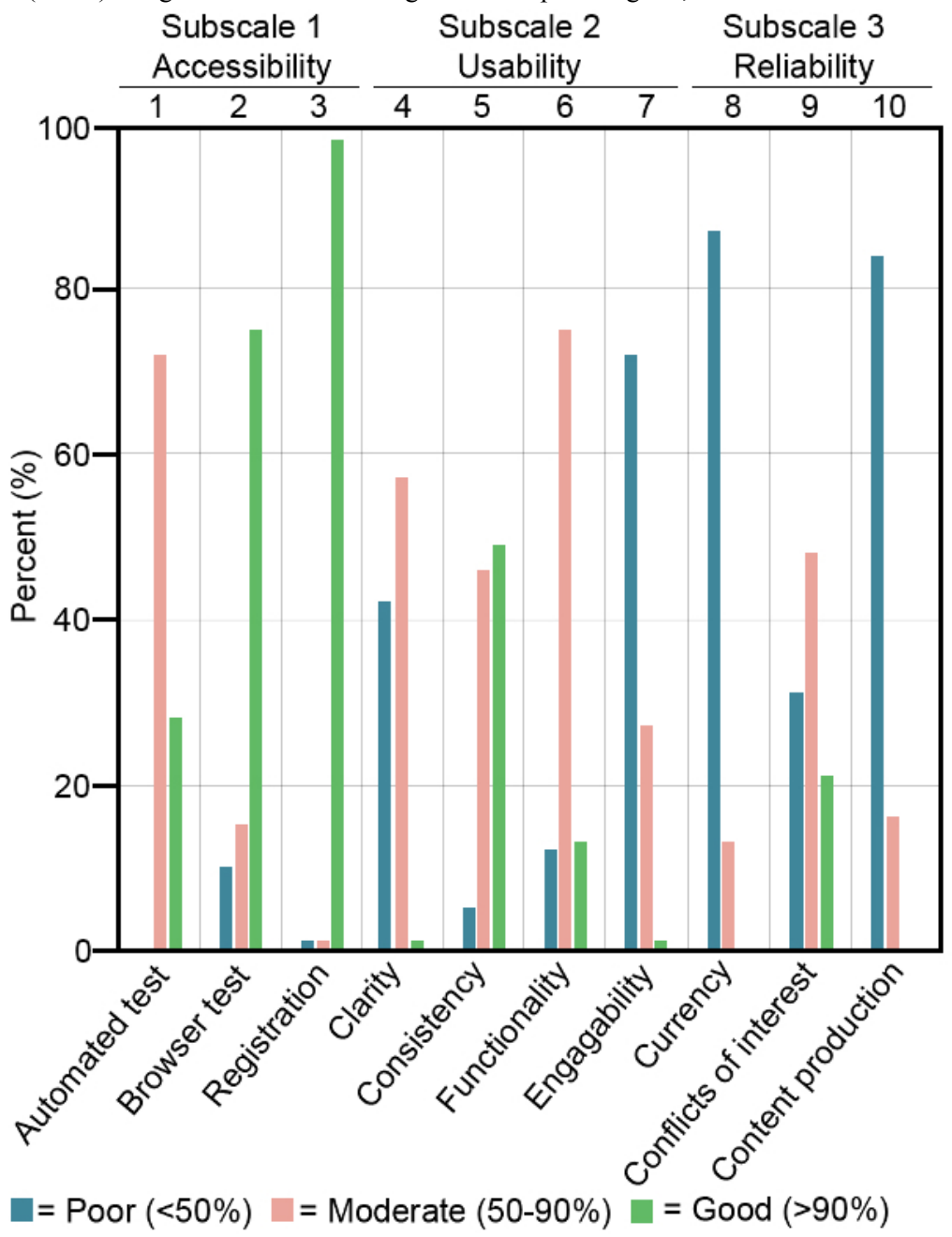




\section{Discussion}

\section{Principal Results}

We searched the Internet with different key terms to find publicly available patient information following a prenatal diagnosis of a congenital heart defect. Hits ranged from 350,000 to $67,500,000$ and 67 of 600 screened websites were included in the study. Over a third $(37 \%, 25 / 67)$ of the websites were affiliated with independent information sources, whereas a quarter $(25 \%, 17 / 67)$ were affiliated with hospitals/clinics. The majority of the information on the websites $(76 \%, 51 / 67)$ could not be attributed to an author. A minority of the websites contained information regarding certain prenatal aspects, that is, common feelings following prenatal diagnosis of CHD, precision of prenatal diagnosis, delivery, risks of CHD in future pregnancy, fetal intervention, termination of pregnancy, and care during pregnancy. Furthermore, the majority of the included websites were scored very poor by the DISCERN instrument with regard to information about effects of no treatment, support for shared decision making, achievement of its aims, explicit aims, risks of each treatment, how treatment choices affect overall quality of life, and areas of uncertainty. The reliability of the included websites was poor according to both the DISCERN instrument and the LIDA tool, particularly regarding currency, content production, aims of website, and areas of uncertainty. However, the accessibility and usability of the included websites were sufficient.

The literature suggests that the overwhelming number of websites found when searching the Web for information leads to information overload and searching difficulties [5,12,24]. The fact that it is difficult to find relevant information on the Internet is exemplified in this study: $39.3 \%(236 / 600)$ of the screened websites were irrelevant. Thus, it is possible that persons seeking information about CHD miss accurate and valuable information or give up information retrieval via the Internet because of difficulties in finding relevant sources. This difficulty might be enhanced by the fact that cardiologists seldom give recommendations on websites in connection with the diagnosis [17]. Health care professionals need to be aware that parents of children with CHD rank information regarding websites at the time of diagnosis as more important than cardiologists [25]. Consequently, as health care consumers are increasingly using the Internet to search for information [1-4], health care professionals need to address these circumstances and actively strive to recommend and provide accurate and reliable high-quality information online.

It seems that the websites target families following a postnatal diagnosis or women opting to continue the pregnancy. Previous research suggests that induced abortion is viewed as a socially unacceptable and stigmatizing procedure [26], independent of state laws on pregnancy termination [27]. It could be speculated that this perspective influenced the content of the included websites, as few contained information regarding termination as an option following a prenatal diagnosis of CHD.

The Internet may provide inaccurate and biased material $[5,28,29]$. It is imperative that pregnant women make informed decisions regarding whether to continue or terminate the pregnancy, which may be hindered by unreliable information sources found online. The majority of the websites in this study had poor reliability in a number of areas, including currency, conflicts of interest, and content production. The importance of current and unbiased information is especially important in the context of the rapidly expanding and evolving field of fetal cardiology, in order to promote informed decisions.

Health literacy, that is, the degree to which individuals have the capacity to obtain, process, and understand the health information and services needed to make appropriate decisions [30], is an important concept when discussing disparities in health information comprehension. Illustrations as a complement to oral information can substantially increase comprehension of health information, are especially helpful for those with poor health literacy [31], and are desired in connection with initial diagnosis [12]. However, animations and illustrations were scarce among the reviewed Web pages. It is therefore possible that the information online is not suited for those with poor health literacy. Health care professionals need to acknowledge this and provide pedagogic tools to promote patient comprehension and equal care.

\section{Strengths and Limitations}

This study did not evaluate the scientific quality of the reviewed websites, nor did it assess the accuracy of the information found, that is, if the included websites contained any inaccurate or misleading information. Furthermore, it is possible that the key terms do not fully represent the online landscape of websites about CHD and that other results would have emerged with different search methods. However, according to previous research, the majority of health information seekers use search engines as their primary source [1,32], and the search engines used in this study are at present the most commonly used [18]. Moreover, the searches yielded 136/600 (22.7\%) duplicate websites, indicating saturation and that the searches do represent the online landscape.

The DISCERN instrument and LIDA tool are based on subjective ratings. Only the first author conducted the assessments, and this could imply poor generalizability, and perhaps also a certain bias. The DISCERN instrument, developed and designed to help users of consumer health information judge the quality of written information, has been found to be consistently understood as well as transferable to different specialties (eg, [20,23,33,34]). Furthermore, the first author is a nurse, which could possibly indicate different views than non-professionals and thus different scorings. However, previous research suggests that scorings are not dependent on previous knowledge of the specific condition [22], and it has been concluded that health professionals score DISCERN similarly to non-professionals when assessing health information [33]. Taken together, we find it reasonable to assume that the main outcomes from this study would have been similar even with another evaluator or with more than one evaluator.

Approximately 25\% (17/67) of the websites were affiliated with hospital/clinics, and 76\% (51/67) could not be attributed to an author. Consequently, it is important to bear in mind that the information found on the included websites may differ from the 
information provided by health care professionals following a diagnosis of CHD.

\section{Suggestions for Future Research}

It remains unclear if websites about congenital heart defects following a prenatal diagnosis contain accurate and suitable information. This needs to be evaluated in future studies by health professionals within fetal/pediatric cardiology and persons with experience of a prenatal diagnosis of a CHD.

It has been reported that expectant parents want more information than that provided by health care professionals following a prenatal diagnosis of CHD [17]. The results from this study, however, indicate that existing websites do not adequately supplement counseling. Development of an information source via the Internet would enable expectant parents to access accurate and tailored information that complements the standard counseling offered today. In order to evaluate such tools, national, or even international, research collaborations are needed.

Easily accessible information on the Internet influences the conditions for doctor-patient interaction [35]. What can be communicated by the doctor, and acknowledged by the patient, always depends on the previous knowledge and perspective that the patient has developed in their own information seeking. Thus, more knowledge is needed on the communication chains in which the patients build their knowledge and understanding.
The linguistic readability of the websites was not assessed in this study. Neither was patients' interpretation and evaluation of the information investigated. Several models for mechanical syntactic analysis, in order to measure readability, were developed in the early years of text linguistics, focusing mainly on factors such as word length and syntactic complexity [36,37]. Similar models have been used to assess medical information $[23,34]$. Later research in computational linguistics suggests that measures of semantics and discourse cohesion, that is, "content", show higher correlations with reported readability [38]. To gain a deeper understanding of Web texts, high-quality qualitative text analytical studies are needed. Preferably, such studies should be combined with reader interviews, focusing on interpretation and comprehension. Furthermore, additional research is needed in order to understand how different types of illustrations can provide relevant understanding of the disease.

\section{Conclusions}

The reviewed websites do not adequately supplement counseling from health care professionals following a prenatal diagnosis of CHD. Difficulties in finding relevant information sources using Web search engines and quality deficits on websites are an incentive for health professionals to take an active part in providing adequate and reliable information online about $\mathrm{CHD}$. Future websites need to have a clearer prenatal perspective to become a source of knowledge for prospective parents seeking information online following diagnosis.

\section{Acknowledgments}

This study was financed by grants from Uppsala County Council, Uppsala-Örebro Regional Research Council. Dr Bergman was also supported by Riksbankens Jubileumsfond (RJ).

\section{Authors' Contributions}

The authors contributed to the paper as follows: TC, GB, AMK, and EM conceived and designed the study; TC collected data; TC and EM analyzed the data; TC, AMK, and EM wrote the paper; GB did a critical revision of the manuscript; TC, GB, AMK, and EM approved the final draft.

\section{Conflicts of Interest}

None declared.

\section{References}

1. Fox S, Duggan M. Pew Research Center. 2013 Jan 15. Health online 2013 URL: http://www.pewinternet.org/files/old-media/ /Files/Reports/PIP HealthOnline.pdf [accessed 2014-05-12] [WebCite Cache ID 6PVxzeIHx]

2. Kummervold PE, Chronaki CE, Lausen B, Prokosch HU, Rasmussen J, Santana S, et al. eHealth trends in Europe 2005-2007: a population-based survey. J Med Internet Res 2008;10(4):e42 [FREE Full text] [doi: 10.2196/jmir.1023] [Medline: 19017584]

3. Larsson M. A descriptive study of the use of the Internet by women seeking pregnancy-related information. Midwifery 2009 Feb;25(1):14-20. [doi: 10.1016/j.midw.2007.01.010] [Medline: 17408822]

4. Papen U. Conceptualising information literacy as social practice: a study of pregnant women's information practices. Information Research 2013 Jun;18(2):280.

5. Cline RJ, Haynes KM. Consumer health information seeking on the Internet: the state of the art. Health Educ Res 2001 Dec;16(6):671-692 [FREE Full text] [Medline: 11780707]

6. Eysenbach G, Powell J, Kuss O, Sa ER. Empirical studies assessing the quality of health information for consumers on the world wide web: a systematic review. JAMA 2002 May;287(20):2691-2700. [Medline: 12020305] 
7. Hesse BW, Nelson DE, Kreps GL, Croyle RT, Arora NK, Rimer BK, et al. Trust and sources of health information: the impact of the Internet and its implications for health care providers: findings from the first Health Information National Trends Survey. Arch Intern Med 2005 Dec;165(22):2618-2624. [doi: 10.1001/archinte.165.22.2618] [Medline: 16344419]

8. Bergman G, Borgström E, Lundell B, Sonesson SE. [Improved prenatal diagnosis of congenital heart defects. A follow-up study of prenatal ultrasound screening]. Lakartidningen 2008;105(12-13):899-903. [Medline: 18461855]

9. Marek J, Tomek V, Skovránek J, Povysilová V, Samánek M. Prenatal ultrasound screening of congenital heart disease in an unselected national population: a 21-year experience. Heart 2011 Jan;97(2):124-130. [doi: 10.1136/hrt.2010.206623] [Medline: 21163892]

10. Allan LD, Huggon IC. Counselling following a diagnosis of congenital heart disease. Prenat Diagn 2004 Dec 30;24(13):1136-1142. [doi: 10.1002/pd.1071] [Medline: 15614846]

11. Menahem S, Grimwade J. Counselling strategies in the prenatal diagnosis of major heart abnormality. Heart Lung Circ 2004 Sep;13(3):261-265. [doi: 10.1016/j.hlc.2004.06.009] [Medline: 16352205]

12. Karlsson AM, Melander Marttala U, Mattsson E. [We can not show a normal heart: Communicative praxis in connection to heart defects in fetus]. Svenskans beskrivning 2014;33:193-213.

13. Sharland G. Fetal cardiac screening: why bother? Arch Dis Child Fetal Neonatal Ed 2010 Jan;95(1):F64-F68. [doi: 10.1136/adc.2008.151225] [Medline: $\underline{20019198]}$

14. Vandvik IH, Førde R. Ethical issues in parental decision-making. An interview study of mothers of children with hypoplastic left heart syndrome. Acta Paediatr 2000 Sep;89(9):1129-1133. [Medline: 11071097]

15. Wool C. Systematic review of the literature: parental outcomes after diagnosis of fetal anomaly. Adv Neonatal Care 2011 Jun;11(3):182-192. [doi: 10.1097/ANC.0b013e31821bd92d] [Medline: 21730912]

16. Brosig CL, Whitstone BN, Frommelt MA, Frisbee SJ, Leuthner SR. Psychological distress in parents of children with severe congenital heart disease: the impact of prenatal versus postnatal diagnosis. J Perinatol 2007 Nov;27(11):687-692. [doi: 10.1038/sj.jp.7211807] [Medline: 17717519]

17. Hilton-Kamm D, Sklansky M, Chang RK. How not to tell parents about their child's new diagnosis of congenital heart disease: an Internet survey of 841 parents. Pediatr Cardiol 2014 Feb;35(2):239-252. [doi: 10.1007/s00246-013-0765-6] [Medline: 23925415]

18. eBizMBA. 2014. Top 15 most popular search engines: May 2014 URL: http://www.ebizmba.com/articles/search-engines [accessed 2014-05-12] [WebCite Cache ID 6PVzUmkSd]

19. Graneheim UH, Lundman B. Qualitative content analysis in nursing research: concepts, procedures and measures to achieve trustworthiness. Nurse Educ Today 2004 Feb;24(2):105-112. [doi: 10.1016/j.nedt.2003.10.001] [Medline: 14769454]

20. Charnock D. Discern online.: University of Oxford and The British Library; 1998. The DISCERN handbook: quality criteria for consumer health information on treatment choices URL: http://www.discern.org.uk/discern.pdf [accessed 2014-05-12] [WebCite Cache ID 6PVzbZzIL]

21. Minervation. 2007. The LIDA instrument: minervation validation instrument for health care web sites URL: http://www. minervation.com/wp-content/uploads/2011/04/Minervation-LIDA-instrument-v1-2.pdf [accessed 2014-05-12] [WebCite Cache ID 6PVzhVPIO]

22. Charnock D, Shepperd S, Needham G, Gann R. DISCERN: an instrument for judging the quality of written consumer health information on treatment choices. J Epidemiol Community Health 1999 Feb;53(2):105-111 [FREE Full text] [Medline: $\underline{10396471]}$

23. Grewal P, Alagaratnam S. The quality and readability of colorectal cancer information on the internet. Int J Surg 2013 Mar;11(5):410-413. [doi: 10.1016/j.ijsu.2013.03.006] [Medline: 23523948]

24. Wathen CN, Harris RM. "I try to take care of it myself." how rural women search for health information. Qual Health Res 2007 May;17(5):639-651. [doi: 10.1177/1049732307301236] [Medline: 17478646]

25. Arya B, Glickstein JS, Levasseur SM, Williams IA. Parents of children with congenital heart disease prefer more information than cardiologists provide. Congenit Heart Dis 2013 Feb;8(1):78-85 [FREE Full text] [doi: 10.1111/j.1747-0803.2012.00706.x] [Medline: 22891764]

26. Astbury-Ward E, Parry O, Carnwell R. Stigma, abortion, and disclosure--findings from a qualitative study. J Sex Med 2012 Dec;9(12):3137-3147. [doi: 10.1111/j.1743-6109.2011.02604.x] [Medline: 22239919]

27. Shellenberg KM, Moore AM, Bankole A, Juarez F, Omideyi AK, Palomino N, et al. Social stigma and disclosure about induced abortion: results from an exploratory study. Glob Public Health 2011 Jul;6 Suppl 1:S111-S125. [doi: 10.1080/17441692.2011.594072] [Medline: 21745033]

28. Cooke A. Quality of health and medical information on the Internet. Clin Perform Qual Health Care 1999 Dec;7(4):178-185. [Medline: 10947392]

29. Resnik DB. Patient access to medical information in the computer age: ethical concerns and issues. Camb Q Healthc Ethics 2001;10(2):147-54; discussion 154-6. [Medline: 11302091]

30. Nielsen-Bohlman L, Panzer AM, Hamlin B, Kindig DA. Health literacy: a prescription to end confusion. Washington, DC: National Academies Press; 2004. 
31. Houts PS, Doak CC, Doak LG, Loscalzo MJ. The role of pictures in improving health communication: a review of research on attention, comprehension, recall, and adherence. Patient Educ Couns 2006 May;61(2):173-190. [doi: 10.1016/j.pec.2005.05.004] [Medline: 16122896]

32. Harris interactive. 2011. The Growing Influence and Use Of Health Care Information Obtained Online URL: http://www. harrisinteractive.com/vault/HI-Harris-Poll-Cyberchondriacs-2011-09-15.pdf [accessed 2014-05-12] [WebCite Cache ID 6PW0VrtSp]

33. Griffiths KM, Christensen H. Website quality indicators for consumers. J Med Internet Res 2005;7(5):e55 [FREE Full text] [doi: 10.2196/jmir.7.5.e55] [Medline: 16403719 ]

34. McKearney TC, McKearney RM. The quality and accuracy of internet information on the subject of ear tubes. Int $\mathrm{J}$ Pediatr Otorhinolaryngol 2013 Jun;77(6):894-897. [doi: 10.1016/j.ijporl.2013.03.021] [Medline: 23587675]

35. Freebody P, Freiberg J. Health literacy as a social practice: response to Nutbeam. Literacy and Numeracy Studies 1999;9(2):57-66.

36. Björnsson CH. [Readability]. Stockholm: Liber; 1968.

37. Kincaid J, Fishburne R, Rogers R, Chissom B. Derivation of new readability formulas (Automated Readability Index, Fog Count and Flesch Reading Ease Formula) for Navy enlisted personnel. Tech Repp 1975;8:e75.

38. Pitler E, Nenkova A. Revisiting readability: a unified framework for predicting text quality. 2008 Presented at: Proceedings of the Conference on empirical methods in natural language processing; 2008; Honolulu, Hawaii p. 186-195.

\section{Abbreviations \\ CHD: congenital heart defect}

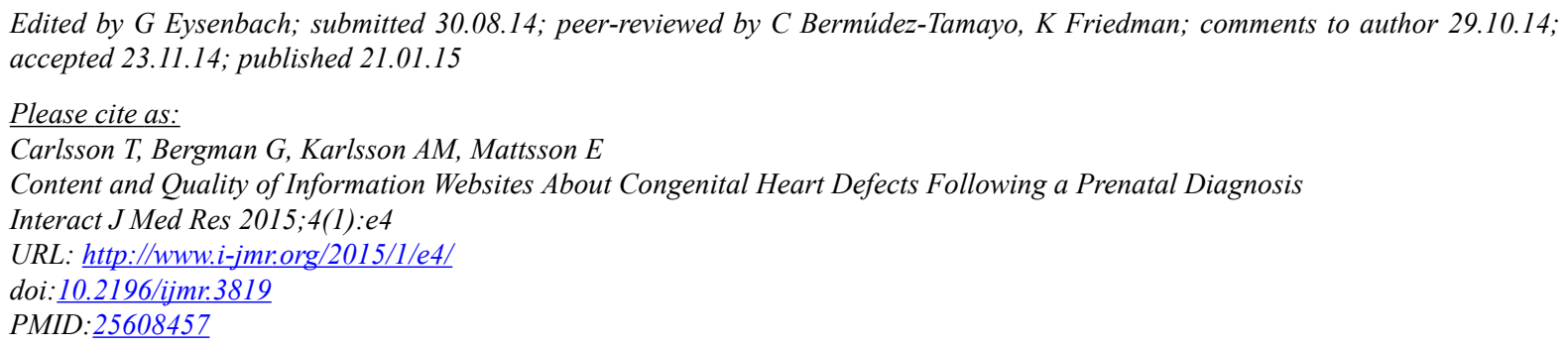

(C) Tommy Carlsson, Gunnar Bergman, Anna-Malin Karlsson, Elisabet Mattsson. Originally published in the Interactive Journal of Medical Research (http://www.i-jmr.org/), 21.01.2015. This is an open-access article distributed under the terms of the Creative Commons Attribution License (http://creativecommons.org/licenses/by/2.0/), which permits unrestricted use, distribution, and reproduction in any medium, provided the original work, first published in the Interactive Journal of Medical Research, is properly cited. The complete bibliographic information, a link to the original publication on http://www.i-jmr.org/, as well as this copyright and license information must be included. 